$$
\text { MT-DP - 2012/ } 5
$$

\title{
Stochastic Bankruptcy Games
}

HELGA HABIS - P. JEAN-J ACQUES HERINGS 
Discussion papers

MT-DP - 2012/5

Institute of Economics, Research Centre for Economic and Regional Studies,

Hungarian Academy of Sciences

KTI/ IE Discussion Papers are circulated to promote discussion and provoque comments. Any references to discussion papers should clearly state that the paper is preliminary. Materials published in this series may subject to further publication.

Stochastic Bankruptcy Games

Authors:

Helga Habis

junior research fellow

Institute of Economics, Hungarian Academy of Sciences

Department of Microeconomics, Corvinus University of Budapest

email: habis@econ.core.hu

P. J ean-J acques Herings

Professor of Microeconomics

Department of Economics, Universiteit Maastricht

E-mail: P.Herings@algec.unimaas.nl

February 2012

ISBN 978-615-5024-97-9

ISSN $1785377 \mathrm{X}$ 


\title{
Stochastic Bankruptcy Games
}

\author{
Helga Habis - P. Jean-Jacques Herings
}

\begin{abstract}
We study bankruptcy games where the estate and the claims have stochastic values. We use the Weak Sequential Core as the solution concept for such games. We test the stability of a number of well known division rules in this stochastic setting and find that most of them are unstable, except for the Constrained Equal Awards rule, which is the only one belonging to the Weak Sequential Core.
\end{abstract}

Keywords: transferable utility games, uncertainty, weak sequential core, bankruptcy games

JEL classification: C71, C73 


\section{Sztochasztikus csődjátékok}

\section{Habis Helga - P. J ean-J acques Herings}

\section{Összefoglaló}

Olyan csődjátékokat vizsgálunk, amelyekben a felosztandó vagyon és a követelések értéke is sztochasztikus változó. A játék megoldására a gyenge szekvenciális magot alkalmazzuk. Számos jól ismert felosztási szabály stabilitását megvizsgáljuk ebben a sztochasztikus környezetben, és azt találjuk, hogy legtöbbjük nem stabil. Az egyetlen kivétel a korlátos egyenlő díjazás szabálya. Ez az egyetlen olyan szabály, amely eleme a gyenge szekvenciális magnak.

Tárgyszavak: átruházható hasznosságú játékok, bizonytalanság, gyenge szekvenciális mag, csődjátékok

JEL kód: C71, C73 


\title{
Stochastic Bankruptcy Games
}

\author{
Helga Habis* and P. Jean-Jacques Herings ${ }^{\dagger}$
}

February 2, 2012

\begin{abstract}
We study bankruptcy games where the estate and the claims have stochastic values. We use the Weak Sequential Core as the solution concept for such games. We test the stability of a number of well known division rules in this stochastic setting and find that most of them are unstable, except for the Constrained Equal Awards rule, which is the only one belonging to the Weak Sequential Core.
\end{abstract}

Keywords: transferable utility games, uncertainty, weak sequential core, bankruptcy games

JEL Classification: C71, C73

\section{Introduction}

The classical bankruptcy problem originating in the Talmud has drawn the attention of game theorists a long time ago. In the original Talmudic version, there is a dying man who has three wives. Upon his death his estate is to be divided among the wives who

\footnotetext{
${ }^{*}$ Institute of Economics, Hungarian Academy of Sciences, and Department of Microeconomics, Corvinus University of Budapest, Fővám tér 8., 1093, Budapest, Hungary. E-mail: helga.habis@uni-corvinus.hu. The author would like to thank the Hungarian Academy of Sciences for the financial support under the Momemtum Programme (LD-004/2010) and OTKA-101106.

${ }^{\dagger}$ Department of Economics, Maastricht University, P.O. Box 616, 6200 MD, Maastricht, The Netherlands. E-mail: P.Herings@maastrichtuniversity.nl. The author would like to thank the Netherlands Organization for Scientific Research (NWO) for financial support.
} 
have claims over the estate, where it is assumed that the sum of these claims exceeds the worth of the estate. The question is how this division or allocation should be done, based on the claims of the players. The game theoretic relevance of this issue was first noticed by O'Neill (1982), who has transformed the original problem into a cooperative game. Later, Aumann and Maschler (1985) also analyzed the problem in a game theoretic setup and related the Talmudic solution to the nucleolus. Since then the bankruptcy problem triggered a wide range of literature with many applications, interpretations and extensions. Many allocation rules have been suggested as a solution; a thorough inventory of them can be found in Thomson (2003).

The entire literature on bankruptcy games assumes that the value of the estate, as well as the value of the claims, are deterministic. However, prior to the bankruptcy situation, typically these values are stochastic as they depend on currently unknown future market values. Nevertheless, coalitions of players can form prior to the resolution of uncertainty and they can discuss divisions of the estate conditional on its value and conditional on their claims. In this paper we therefore introduce the class of stochastic bankruptcy games.

A stochastic bankruptcy game is a special case of a transferable utility game with uncertainty, or briefly TUU-game, as introduced in Habis and Herings (2011). A TUUgame is a two-period cooperative game. In period 0, agents may decide to cooperate or not, facing uncertainty about the state of nature in period 1. In period 1, one state of nature materializes and a state-dependent TU-game is played. When applied to bankruptcy games, we have that the worth of the estate and the claims of the agents (wives) my depend on the state of nature; i.e. in each state of nature a different bankruptcy game may be played.

In a classical, static cooperative game it is implicitly assumed that the players can make fully binding agreements on the allocation of payoffs. When such an assumption is made in our stochastic setting, then coalitions can make fully binding state-contingent allocations of payoffs in period 0 , and the game becomes formally equivalent to a non-transferable utility game. We, on the other hand, study the case where agents cannot make such fully binding agreements. Instead, agents will not stick to their agreements concerning the future if after the resolution of uncertainty, they are better off when deviating. Hence, we only allow for self-enforcing agreements.

An agreement is said to be self-enforcing if there is no coalition of players with a credible deviation in some period. All deviations by singleton coalitions that lead to higher utility 
are credible. More generally, credible deviations are inductively defined by the requirement that a deviation is credible in some period if there is no further credible deviation by any sub-coalition, now or in the future. In static transferable utility games, the set of deviations and the set of credible deviations coincide (Ray, 1989).

In our setting, credibility plays a crucial role and leads to the concept of the Weak Sequential Core, introduced by Kranich, Perea, and Peters (2005) for finite deterministic sequences of TU-games, by Predtetchinski, Herings, and Perea (2006) for two-period exchange economies with incomplete markets, and by Habis and Herings (2011) for TUUgames. Moreover, Habis and Herings (2011) give a characterization of the Weak Sequential Core, and show its non-emptiness if all the state-contingent games played in period 1 are convex. Since Aumann and Maschler (1985) show that bankruptcy games are convex, the Weak Sequential Core of stochastic bankruptcy games is non-empty.

Similarly to core-compatibility in a static problem, we use the Weak Sequential Core to test the robustness to uncertainty of the most important allocation rules as suggested in the literature; the Proportional rule, the Adjusted Proportional rule, the Constrained Equal Awards rule, the Constrained Equal Losses rule, and the Talmud rule. It is wellknown that all rules are stable in a deterministic bankruptcy game, being an element of the classical core. In a stochastic setting, however, each of them is unstable, with the exception of the Constrained Equal Awards rule.

The outline of the paper is as follows. We specify the TUU model in Section 2 and give the formal definition of the Weak Sequential Core in Section 3. The bankruptcy problem itself and the division rules are analyzed in Section 4. Section 5 concludes.

\section{Preliminaries}

Consider a game with two periods, $t \in T=\{0,1\}$. In period 1 , one state of nature $s$ out of a finite set of states of nature $S$ occurs. We define the state of nature for period 0 as state 0 , so the set of all states is $S^{\prime}=\{0\} \cup S$. In period 1 the players are involved in a cooperative game with transferable utility, or briefly TU-game, where the game itself is allowed to be state-dependent. Period 0 serves as a point in time prior to the resolution of uncertainty.

The TU-game $\Gamma_{s}$ played in state $s \in S$ is a pair $\left(N, v_{s}\right)$, where $N=\{1,2, \ldots, n\}$ is the set of players and $v_{s}: 2^{N} \rightarrow \mathbb{R}$ is a characteristic function which assigns to each 
coalition $C \subseteq N$ its worth $v_{s}(C)$, with the convention that $v(\emptyset)=0$. Player $i \in N$ evaluates his payoffs by a utility function $u^{i}: \mathbb{R}^{S} \rightarrow \mathbb{R}$, which assigns to every profile of payoffs $x^{i}=\left(x_{1}^{i}, \ldots, x_{S}^{i}\right) \in \mathbb{R}^{S}$ a utility level $u^{i}\left(x^{i}\right)$ and is assumed to be continuous and state-separable, i.e. $u^{i}\left(x^{i}\right)=\sum_{s \in S} u_{s}^{i}\left(x_{s}^{i}\right)$, where $u_{s}^{i}\left(x_{s}^{i}\right)$ is monotonically increasing. A well-known example of utility functions satisfying these assumptions are von NeumannMorgenstern utility functions.

A TU-game with uncertainty is defined by Habis and Herings (2011) as follows.

Definition 2.1. A $T U$-game with uncertainty ( $T U U$-game) $\Gamma$ is a tuple $(N, S, v, u$ ) where $v=\left(v_{1}, \ldots, v_{S}\right)$ and $u=\left(u^{1}, \ldots, u^{n}\right)$.

Note that there are no payoffs in state 0 . State 0 is merely introduced as a point in time when the players face the uncertainty in the future and may decide to cooperate. Payoffs in state 0 could be incorporated into our model but our main interest is in analyzing the effect of future uncertainty on the stability of payoff allocations.

Another observation is that when the cardinality of $S$ is one, the concept of a TUUgame collapses with the one of a TU-game. In the absence of uncertainty, all monotonic transformations of utility functions are equivalent, and it is without loss of generality to take $u^{i}\left(x^{i}\right)=x^{i}$. Our interest is obviously in the cases with non-degenerate uncertainty.

The central question in a TUU-game is how the worth $v_{s}(N)$ of the grand coalition is distributed among its members in every state $s \in S$. A distribution of worth, represented by a matrix $x=\left(x^{1}, \ldots, x^{n}\right) \in \mathbb{R}^{S \times N}$, is called an allocation. The state-s component $x_{s}=\left(x_{s}^{1}, \ldots, x_{s}^{n}\right) \in \mathbb{R}^{N}$ of an allocation is referred to as the allocation in state $s \in S$. The total worth obtained by coalition $C$ in state $s$ is $x_{s}(C)=\sum_{i \in C} x_{s}^{i}$. An allocation for a coalition $C$ is a matrix $x^{C}=\left(x^{i}\right)_{i \in C} \in \mathbb{R}^{S \times C}$, with a state-s component $x_{s}^{C} \in \mathbb{R}^{C}$. The restriction of a TUU-game $\Gamma$ to coalition $C$ is denoted by $(\Gamma, C)$.

\section{The Weak Sequential Core WSC $(\Gamma)$}

We study the stability of allocations in a TUU-game $\Gamma$. In general, $\bar{x}$ is stable if there is no state $s^{\prime} \in S^{\prime}$ and coalition $C \subseteq N$ such that $C$ has a profitable deviation from $\bar{x}$ at $s^{\prime}$. There are various ways in which the notion of profitable deviation might be formulated. Here we concentrate on the Weak Sequential Core, introduced in Kranich, Perea, and Peters (2005) for finite deterministic sequences of TU-games, in Predtetchinski, Herings, 
and Perea (2006) for two-period exchange economies with incomplete markets, and in Habis and Herings (2011) for TUU-games.

Full commitment may be a strong and unrealistic assumption in the presence of time and uncertainty. Once the state of nature is known, there are typically players which have no incentives to stick to the previously arranged allocation of payoffs. One problem with full commitment is that the state of nature may not be verifiable by an outside court, implying that previously made arrangements cannot be enforced. The Weak Sequential Core applies to the case with absence of commitment and looks for agreements which are self-enforcing.

Following Habis and Herings (2011), we first define what allocations and thereby deviations are feasible for coalitions at different states, then we formalize the notion of credible deviations and finally we define the Weak Sequential Core of a TUU-game. We start with feasibility at future states.

Definition 3.1. Let some allocation $\bar{x}$ be given. The allocation $x^{C}$ is feasible for a coalition $C$ at state $s \in S$ if

$$
\begin{aligned}
x_{-s}^{C} & =\bar{x}_{-s}^{C}, \\
x_{s}(C) & \leq v_{s}(C) .
\end{aligned}
$$

The first condition requires that the members of a coalition take allocations outside state $s$ as given. Since utility functions are assumed to be state-separable, this assumption is harmless. According to the second condition, in state $s$ the members of a coalition can redistribute at most their worth.

We turn next to feasibility as state 0 .

Definition 3.2. Let some allocation $\bar{x}$ be given. The allocation $x^{C}$ is feasible for a coalition $C$ at state 0 if

$$
x(C) \leq v(C) .
$$

Note that this concept says that the allocation must be feasible for coalition $C$ in every state; it requires $\sum_{i \in C} x_{s}^{i} \leq v_{s}(C)$ to hold for all states in period $t=1$.

We continue by defining deviations as feasible allocations that improve the utility of every coalition member. 
Definition 3.3. Let some allocation $\bar{x}$ be given. A coalition $C$ can deviate from $\bar{x}$ at state $s^{\prime} \in S^{\prime}$ if there exists a feasible allocation $x^{C}$ for $C$ at $s^{\prime}$ such that

$$
u^{i}\left(x^{i}\right)>u^{i}\left(\bar{x}^{i}\right) \text {, for all } i \in C .
$$

The allocation $x^{C}$ in Definition 3.3 is referred to as a deviation. Definition 3.3 can be extended in an obvious way to define deviations from an allocation $x^{C}$ by a sub-coalition $D$ of $C$.

Since deviations should be self-enforcing, we introduce the notion of credible deviations. In defining credibility, we follow the approach developed in Ray (1989) for the static case. Ray (1989) shows that in a static environment the set of deviations coincides with the set of credible deviations. This is no longer true in our setting.

Credible deviations are defined recursively and by backwards induction. At any future state, any deviation by a singleton coalition is credible. A 2-player coalition has a credible deviation at a future state if there is no singleton sub-coalition with a credible counterdeviation at that state. A credible deviation at a future state for an arbitrary coalition is then defined by recursion. More formally, a credible deviation at state $s \in S$ by a coalition $C$ is defined as follows.

Definition 3.4. Let some allocation $\bar{x}$ be given. Any deviation $x^{C}$ from $\bar{x}$ at state $s \in S$ by a singleton coalition is credible. A deviation $x^{C}$ from $\bar{x}$ at state $s$ by coalition $C$ is credible if there is no sub-coalition $D \subsetneq C$ such that $D$ has a credible deviation from $x^{C}$ at state $s$.

At state 0 , again, any deviation by a singleton coalition is credible. A 2-player coalition has a credible deviation at state 0 if there is no singleton sub-coalition with a credible counter-deviation at any state, current or future. A credible deviation at state 0 by an arbitrary coalition is then defined by recursion. More formally, we have the following definition.

Definition 3.5. Let some allocation $\bar{x}$ be given. Any deviation $x^{C}$ from $\bar{x}$ at state 0 by a singleton coalition is credible. A deviation $x^{C}$ from $\bar{x}$ at state 0 by coalition $C$ is credible if there is no sub-coalition $D \subsetneq C$ and state $s^{\prime} \in S^{\prime}$ such that $D$ has a credible deviation from $x^{C}$ at $s^{\prime}$.

Definition 3.6. The Weak Sequential Core $\operatorname{WSC}(\Gamma)$ of the game $\Gamma$ is the set of feasible allocations $\bar{x}$ for the grand coalition from which no coalition ever has a credible deviation. 
It is possible to characterize the Weak Sequential Core by means of the classical core of suitably chosen subgames.

Definition 3.7. The Core $\mathrm{C}(N, v)$ of a $\mathrm{TU}$-game $(N, v)$ is the collection of allocations $\bar{x}$ such that $\bar{x}(N)=v(N)$ and there is no coalition $C$ that can improve upon $\bar{x}$.

Habis and Herings (2011) provides the following characterization of the Weak Sequential Core.

Theorem 3.8. The following two statements are equivalent:

(a) $\bar{x} \in \operatorname{WSC}(\Gamma)$,

(b) $\bar{x}$ is such that $\bar{x}_{s} \in \mathrm{C}\left(\Gamma_{s}\right)$ for all $s \in S$, and there is no $C \subset N$ and allocation $x^{C}$ such that $x_{s}^{C} \in \mathrm{C}\left(\Gamma_{s}, C\right)$ for all $s \in S$, and $u^{i}\left(x^{i}\right)>u^{i}\left(\bar{x}^{i}\right)$ for all $i \in C$.

For an allocation to belong to the Weak Sequential Core of the TUU-game $\Gamma$, the allocation should belong to the Core of the TU-game $\Gamma_{s}$ in every state $s \in S$. Moreover, no coalition should be able to pick an element of the Core of the game restricted to $C$ in every state, and in doing so improve utility in an ex ante sense.

The Weak Sequential Core is non-empty if all state-contingent TU-games in the TUUgame are convex.

Definition 3.9. A TU-game $(N, v)$ is convex if for all $C \subset N$ and for all $S \subsetneq T \subset N \backslash C$ it holds that $v(S \cup C)-v(S) \leq v(T \cup C)-v(T)$.

Habis and Herings (2011) proves the following result.

Theorem 3.10. Let the TUU-game $\Gamma$ be such that $\Gamma_{s}$ is convex for all $s \in S$. Then $\operatorname{WSC}(\Gamma) \neq \emptyset$.

The class of convex TU-games admits a wide range of interesting applications. Examples are airport games (Littlechild and Owen, 1973), bankruptcy games (Aumann and Maschler, 1985), sequencing games (Curiel, Pederzoli, and Tijs, 1989) and standard tree games (Granot, Maschler, Owen, and Zhu, 1996). 


\section{Bankruptcy games and division rules}

In this section we analyze the application of the Weak Sequential Core to bankruptcy games. Bankruptcy games originate in a fundamental paper by O'Neill (1982). The problem is based on a Talmudic example, where a man dies, leaving behind an estate, $E$, which is worth less than the sum of his debts. The question is how the estate should be divided among the creditors.

A bankruptcy problem is defined as a pair $(E, d)$, where $d=\left(d^{1}, \ldots, d^{n}\right)$ is the vector of individual debts, and $\sum_{i \in N} d^{i} \geq E \geq 0$. Following Aumann and Maschler (1985), the problem can be transformed into a cooperative game. The characteristic function $v^{E, d}$ is defined to be

$$
v^{E, d}(C)=\max \left\{E-\sum_{i \in N \backslash C} d^{i}, 0\right\}, \quad C \subset N,
$$

so the worth of a coalition $C$ in the game $v^{E, d}$ is that amount of the estate which is not claimed by the complement of $C$. It has been shown by Curiel, Maschler, and Tijs (1987) that $v^{E, d}$ is convex.

A rule is a function that associates with each $(E, d)$ an allocation $x \in \mathbb{R}^{N}$ such that $\sum_{i \in N} x_{i}=E$ and $0 \leq x \leq d$. A thorough inventory of the rules can be found in Thomson (2003). The best-known rule is the Proportional rule (P) which allocates the estate proportional to the claims. The Adjusted Proportional rule (AP) selects the allocation at which each claimant $i$ receives his minimal right $\max \left\{E-\sum_{j \neq i} d^{j}, 0\right\}$, then each claim is revised down accordingly, and finally, the remainder of the estate is divided proportionally to the revised claims. The Constrained Equal Awards rule (CEA) is in the spirit of equality; it assigns equal amounts to all claimants subject to no one receiving more than his claim. More formally, we have the following.

Definition 4.1 (Constrained Equal Awards rule). For $i^{\prime} \in N$, for each $(E, d), \operatorname{CEA}^{i^{\prime}}(E, d)=$ $\min \left\{d^{i^{\prime}}, \alpha\right\}$, where $\alpha \leq \max _{i \in N} d^{i}$ is chosen so that $\sum_{i \in N} \min \left\{d^{i}, \alpha\right\}=E$.

The Constrained Equal Losses rule (CEL), as opposed to the CEA rule, is focusing on losses claimants incur, and makes these losses equal, with no one receiving a negative amount. The recommendation of the Talmud, later formalized in Aumann and Maschler (1985) as the Talmud rule (TR), is a combination of the CEA rule and the CEL rule, depending on the relation of the half-claims and the value of the estate. The Piniles' rule 
(Piniles, 1861) is an application of the CEA rule to the half-claims in two different ways, again depending on the relation of the half-claims and the value of the estate. In our setup it coincides with the Talmud rule. The Constrained Egalitarian rule (Chun, Schummer, and Thomson, 2001) also gives a central role to the half-claims, and guarantees that the awards are ordered as the claims are. In our case it also coincides with the Talmud rule. The Random Arrival rule (RA) takes all the possible orders of claimants arriving one at a time, compensates them fully until money runs out, and takes the arithmetic average over all orders of arrival.

Many rules are related to the solutions of bankruptcy games. The AP rule corresponds to the $\tau$-value (Curiel, Maschler, and Tijs, 1987), the CEA rule to the Dutta-Ray solution (Dutta and Ray, 1989), the TR rule to the prenucleolus (Aumann and Maschler, 1985), and the RA rule to the Shapley value (O'Neill, 1982). Any rule belongs to the Core of the bankruptcy game. Indeed, let $\bar{x}$ be the allocation that the rule associates to the bankruptcy problem $(E, d)$. It holds obviously that $\bar{x}(N)=v(N)=E$. Moreover, we have

$$
v(C)=\max \left\{0, E-\sum_{i \in N \backslash C} d^{i}\right\} \leq \max \left\{0, E-\sum_{i \in N \backslash C} \bar{x}^{i}\right\}=\max \left\{0, \sum_{i \in C} \bar{x}^{i}\right\}=\bar{x}(C),
$$

so no coalition can improve upon $\bar{x}$.

In the original estate division problem of the Talmud a man has 3 wives whose marriage contracts specify that upon his death they should receive 100, 200 and 300 respectively. When the man dies, his estate is found to be worth 100, 200 or 300 in three different scenarios.

The characteristic function of the resulting TU-games, with $d=100,200$ and 300, is shown in Table 1.

Table 1: Characteristic function of estate division

\begin{tabular}{|c||cccccccc|}
\hline$v^{E, d}$ & $\emptyset$ & $\{1\}$ & $\{2\}$ & $\{3\}$ & $\{1,2\}$ & $\{1,3\}$ & $\{2,3\}$ & $\{1,2,3\}$ \\
\hline \hline$v^{100, d}$ & 0 & 0 & 0 & 0 & 0 & 0 & 0 & 100 \\
$v^{200, d}$ & 0 & 0 & 0 & 0 & 0 & 0 & 100 & 200 \\
$v^{300, d}$ & 0 & 0 & 0 & 0 & 0 & 100 & 200 & 300 \\
\hline
\end{tabular}

Table 2 summarizes the outcomes of the rules described before when applied to the estate division problem.

We are interested in the question to what extent the rules lead to allocations that are self-enforcing in the presence of uncertainty regarding the value of the estate and the size 
Table 2: Estate allocation

\begin{tabular}{|l|c||c|c|c|c|c|c|}
\hline Player & Estate & TR & P & AP & CEA & CEL & RA \\
\hline \multirow{4}{*}{$d^{1}=100$} & 100 & $331 / 3$ & $162 / 3$ & $331 / 3$ & $331 / 3$ & 0 & $331 / 3$ \\
& 200 & 50 & $331 / 3$ & 40 & $662 / 3$ & 0 & $331 / 3$ \\
& 300 & 50 & 50 & 50 & 100 & 0 & 50 \\
\hline \multirow{3}{*}{$d^{2}=200$} & 100 & $331 / 3$ & $331 / 3$ & $331 / 3$ & $331 / 3$ & 0 & $331 / 3$ \\
& 200 & 75 & $662 / 3$ & 80 & $662 / 3$ & 50 & $831 / 3$ \\
& 300 & 100 & 100 & 100 & 100 & 100 & 100 \\
\hline \multirow{3}{*}{$d^{3}=300$} & 100 & $331 / 3$ & 50 & $331 / 3$ & $331 / 3$ & 100 & $331 / 3$ \\
& 200 & 75 & 100 & 80 & $662 / 3$ & 150 & $831 / 3$ \\
& 300 & 150 & 150 & 150 & 100 & 200 & 150 \\
\hline
\end{tabular}

of the debts. A stochastic bankruptcy problem is defined as a tuple $(S, E, d, u)$, where $S$ is a finite set of states of nature, $E=\left(E_{s}\right)_{s \in S}$ is the value of the estate in state $s, d=\left(d_{s}\right)_{s \in S}$ is the state-dependent vector of debts, and $u=\left(u^{i}\right)_{i \in N}$ are the continuous, state-separable, weakly monotonic utility functions of the claimants, where $u^{i}: \mathbb{R}^{S} \rightarrow \mathbb{R}$. Extending the approach of Aumann and Maschler (1985) to the stochastic case, we can transform a stochastic bankruptcy problem into a stochastic bankruptcy game $\Gamma=(N, S, v, u)$, the TUU-game where we set

$$
v_{s}(C)=\max \left\{E_{s}-\sum_{i \in N \backslash C} d_{s}^{i}, 0\right\}, \quad s \in S, C \subset N .
$$

The observation that bankruptcy games are convex (Aumann and Maschler, 1985) combined with Theorem 3.10 leads to the following result.

Theorem 4.2. The Weak Sequential Core of a stochastic bankruptcy game $\Gamma=(N, S, v, u)$ is non-empty.

We have already argued that a rule leads to an allocation in the Core of the bankruptcy game. This implies that for a stochastic bankruptcy game, blocking is not possible after the resolution of uncertainty. However, it might be possible to block the allocation described by a rule ex ante.

As an example, consider the estate division problem of the Talmud, where the claims of the three wives are fixed, but the exact value of the estate is uncertain, and the possible 
values 100, 200, and 300 are equally likely. After the uncertainty regarding the estate's value is resolved in period 1 , one of the three TU-games is played, arising from the original three scenarios of the problem. Suppose the wives evaluate the payoffs with the utility function,

$$
u^{i}\left(x^{i}\right)=\sum_{s \in S} \frac{1}{3}\left(1000 x_{s}^{i}-\left(x_{s}^{i}\right)^{2}\right),
$$

whenever $0 \leq x_{s}^{i} \leq 300$ for $s \in S .^{1}$

We demonstrate that the grand coalition has a credible deviation from the allocation specified by all the rules mentioned before at state 0 , with the exception of the Constrained Equal Awards rule. Table 3 lists the credible deviations, denoted by $x$, and Table 4 the implied utilities, as well as the utilities of the allocations $\bar{x}$ implied by the various rules.

Table 3: Credible deviations

\begin{tabular}{|l|r||r|r|r|r|r|}
\hline Player & $E$ & TR & P & AP & CEL & RA \\
\hline \multirow{4}{*}{$d^{1}=100$} & 100 & 25 & 0 & 25 & 0 & 29 \\
& 200 & 40 & 33 & 35 & 0 & 29 \\
& 300 & 70 & 70 & 65 & 0.01 & 60 \\
\hline \multirow{3}{*}{$d^{2}=200$} & 100 & 25 & 30 & 25 & 0 & 34 \\
& 200 & 75 & 63 & 80 & 49 & 83 \\
& 300 & 110 & 108 & 110 & 101.13 & 100 \\
\hline \multirow{3}{*}{$=300$} & 100 & 50 & 70 & 50 & 100 & 37 \\
& 200 & 85 & 104 & 85 & 151 & 88 \\
& 300 & 120 & 122 & 125 & 198.86 & 140 \\
\hline
\end{tabular}

We show next that the Constrained Equal Awards rule belongs to the Weak Sequential Core of the stochastic bankruptcy game quite generally.

Theorem 4.3. For $i \in N$, let the utility function be given by $u^{i}\left(x^{i}\right)=\sum_{s \in S} \rho_{s} w\left(x_{s}^{i}\right)$, where $\rho_{s}$ is the objective probability of state $s$ and $w$ is a differentiable, concave function. Then the allocation following from the Constrained Equal Awards rule belongs to the Weak Sequential Core of the stochastic bankruptcy game $\Gamma=(N, S, v, u)$.

\footnotetext{
${ }^{1}$ Outside this domain the utility function can be anything, as long as it is continuous, state-separable and monotonically increasing.
} 
Table 4: Utilities

\begin{tabular}{|l|c||c|c|c|c|c|}
\hline Player & $u$ & TR & P & AP & CEL & RA \\
\hline \multirow{2}{*}{$d^{1}=100$} & $u^{1}\left(\bar{x}^{1}\right)$ & 42407.41 & 32037.04 & 39374.07 & 0.00 & 37314.81 \\
& $u^{1}\left(x^{1}\right)$ & 42625.00 & 32337.00 & 39641.67 & 3.33 & 37572.67 \\
\hline \multirow{2}{*}{$d^{2}=200$} & $u^{2}\left(\bar{x}^{2}\right)$ & 63865.74 & 61481.48 & 65274.07 & 45833.33 & 66203.70 \\
& $u^{2}\left(x^{2}\right)$ & 63883.33 & 61489.00 & 65291.67 & 45833.91 & 66318.33 \\
\hline \multirow{2}{*}{$d^{3}=300$} & $u^{3}\left(\bar{x}^{3}\right)$ & 76365.74 & 88333.33 & 77774.07 & 125833.33 & 78703.70 \\
& $u^{3}\left(x^{3}\right)$ & 76958.33 & 88466.67 & 78216.67 & 125837.90 & 78762.33 \\
\hline
\end{tabular}

Proof. Let $\bar{x}$ be the allocation following from the Constrained Equal Awards rule. We have already argued that $\bar{x}_{s} \in \mathrm{C}\left(\Gamma_{s}\right)$ holds for all $s \in S$. By 3.8 it remains to be shown that there is no $x^{C}$ such that $x_{s}^{C} \in \mathrm{C}\left(\Gamma_{s}, C\right)$ for all $s \in S$, and $u^{i}\left(x^{i}\right)>u^{i}\left(\bar{x}^{i}\right)$ for all $i \in C$.

Consider a stochastic bankruptcy problem with set of players $C \subset N$, estate in state $s$ equal to $\max \left\{E_{s}-\sum_{i \in N \backslash C} d_{s}^{i}, 0\right\}$ and claims equal to $d_{s}^{i}$ for $i \in C$. The corresponding stochastic bankruptcy game is denoted by $\left(C, S, v^{C},\left(u^{i}\right)_{i \in C}\right)$. Let $\bar{y}^{C}$ be the allocation resulting from the CEA rule.

Note that for $D \subset C$, the worth of coalition $D$ in game $v_{s}^{C}$ coincides with its worth in the original game, since

$$
\begin{aligned}
v_{s}^{C}(D) & =\max \left\{v_{s}^{C}(C)-\sum_{i \in C \backslash D} d_{s}^{i}, 0\right\} \\
& =\max \left\{\max \left\{E_{s}-\sum_{i \in N \backslash C} d_{s}^{i}, 0\right\}-\sum_{i \in C \backslash D} d_{s}^{i}, 0\right\},
\end{aligned}
$$

where either $(a) E_{s}-\sum_{i \in N \backslash C} d_{s}^{i}>0$, and so $v_{s}^{C}(D)=\max \left\{E_{s}-\sum_{i \in N \backslash D} d_{s}^{i}, 0\right\}=v_{s}(D)$, or $(b) E_{s}-\sum_{i \in N \backslash C} d_{s}^{i} \leq 0$, and so $v_{s}^{C}(D)=0=v_{s}(D)$.

We have that $\bar{y}_{s}^{C} \in \mathrm{C}\left(\Gamma_{s}, C\right)$ for all $s \in S$. We show next that $\bar{y}^{C}$ maximizes the sum of the players utilities over allocations $x^{C}$ with $x_{s}^{C} \in \mathrm{C}\left(\Gamma_{s}, C\right)$ for all $s \in S$.

Consider the following constrained maximization problem,

$$
\begin{aligned}
\max _{x^{C}} & \sum_{i \in C} u^{i}\left(x^{i}\right) \\
\text { s.t. } & \sum_{i \in C} x_{s}^{i}=v_{s}(C), \quad s \in S, \\
& \sum_{i \in D} x_{s}^{i} \geq v_{s}(D), \quad s \in S, \emptyset \neq D \subsetneq C,
\end{aligned}
$$


where condition (2) is required for ex post efficiency and inequality (3) is a no-blocking condition. A solution to the maximization problem maximizes the sum of the players' utilities among those allocations that belong to $\mathrm{C}\left(\Gamma_{s}, C\right)$ for all $s \in S$.

We form the Lagrangian,

$$
\mathcal{L}(x, \lambda, \mu)=\sum_{i \in C} \sum_{s \in S} \rho_{s} w\left(x_{s}^{i}\right)-\sum_{s \in S} \mu_{s}\left(\sum_{i \in C} x_{s}^{i}-v_{s}(C)\right)-\sum_{s \in S} \sum_{D \subsetneq C} \lambda_{s}^{D}\left(\sum_{i \in D} x_{s}^{i}-v_{s}(D)\right) .
$$

The first-order conditions, which are necessary and sufficient for a maximum, are given by

$$
\begin{aligned}
\rho_{s} w^{\prime}\left(x_{s}^{i}\right)-\mu_{s}-\sum_{D \subsetneq C \mid D \ni i} \lambda_{s}^{D} & =0, \quad s \in S, i \in C, \\
\sum_{i \in C} x_{s}^{i}-v_{s}(C) & =0, \quad s \in S, \\
\lambda_{s}^{D}\left(\sum_{i \in D} x_{s}^{i}-v_{s}(D)\right) & =0, \quad s \in S, \emptyset \neq D \subsetneq C, \\
\sum_{i \in D} x_{s}^{i}-v_{s}(D) & \geq 0, \quad s \in S, \emptyset \neq D \subsetneq C, \\
\lambda_{s}^{D} & \leq 0, \quad s \in S, \emptyset \neq D \subsetneq C .
\end{aligned}
$$

We will show that together with an appropriate choice of $\lambda$ and $\mu, \bar{y}^{C}$ satisfies these firstorder conditions. Conditions (5) and (7) hold since $\bar{y}_{s}^{C} \in \mathrm{C}\left(\Gamma_{s}, C\right)$ for all $s \in S$. To show that the remaining conditions hold as well, we introduce two subsets of players for each state, and distinguish two cases. For $s \in S$, let $I_{s}=\left\{i \in C \mid \bar{y}_{s}^{i}=d_{s}^{i}\right\}$ be the set of those agents whose claim is fully paid in state $s$.

1. $I_{s}=\emptyset$

For all $\emptyset \neq D \subsetneq C$ we set $\lambda_{s}^{D}=0$, thereby satisfying conditions (6) and (8). Since $I_{s}=\emptyset$, it holds for all $i \in C$ that $\bar{y}_{s}^{i}>d_{s}^{i}$. By the definition of the CEA rule, $\bar{y}_{s}^{i}$ is independent of $i$. It follows that $\rho_{s} w^{\prime}\left(\bar{y}_{s}^{i}\right)$ is also independent of $i$, thus we can define $\mu_{s}=\rho_{s} w^{\prime}\left(\bar{y}_{s}^{i}\right)$ for all $i \in C$ to satisfy condition (4).

\section{2. $I_{s} \neq \emptyset$}

Let $C=\left\{i_{s}^{1}, \ldots, i_{s}^{c}\right\}$, where $d_{s}^{i^{1}} \leq d_{s}^{i^{2}} \leq \ldots \leq d_{s}^{i^{c}}$ and $c$ denotes the cardinality of $C$. Then, using the definition of the CEA rule, for some $k \geq 1, I_{s}=\left\{i_{s}^{1}, \ldots, i_{s}^{k}\right\}$. For $1<j \leq k+1$ we define $D_{s}^{j}=\left\{i_{s}^{j}, \ldots, i_{s}^{c}\right\}$, so $C \backslash D_{s}^{j} \subset I_{s}$ and $C \backslash D_{s}^{k+1}=I_{s}$. We define $\mu_{s}=\rho_{s} w^{\prime}\left(\bar{y}_{s}^{i^{1}}\right)$, i.e. the marginal utility of the player with the lowest claim in state $s$. For $1<j \leq k+1$ we define $\lambda_{s}^{D_{s}^{j}}=\rho_{s} w^{\prime}\left(\bar{y}_{s}^{i^{j}}\right)-\rho_{s} w^{\prime}\left(\bar{y}_{s}^{i^{j-1}}\right)$. By the definition 
of the CEA rule it holds that $\bar{y}_{s}^{i^{j}} \geq \bar{y}_{s}^{i^{j-1}}$, so $\lambda_{s}^{D_{s}^{j}} \leq 0$. For other coalitions $D$ we set $\lambda_{s}^{D}=0$. It follows that condition (8) is satisfied. The definition of the CEA rule and equation (1) imply that

$$
\sum_{i \in D_{s}^{j}} \bar{y}_{s}^{i}=v_{s}(C)-\sum_{i \in C \backslash D_{s}^{j}} \bar{y}_{s}^{i}=\max \left\{E_{s}-\sum_{i \in N \backslash C} d_{s}^{i}, 0\right\}-\sum_{i \in C \backslash D_{s}^{j}} d_{s}^{i} .
$$

Since $\sum_{i \in D_{s}^{j}} \bar{y}_{s}^{i} \geq 0$,

$$
\max \left\{E_{s}-\sum_{i \in N \backslash C} d_{s}^{i}, 0\right\}-\sum_{i \in C \backslash D_{s}^{j}} d_{s}^{i}=\max \left\{E_{s}-\sum_{i \in N \backslash D^{j}} d_{s}^{i}, 0\right\}=v_{s}\left(D_{s}^{j}\right) .
$$

It follows from equation (9) and (10) that $\sum_{i \in D_{s}^{j}} \bar{y}_{s}^{i}-v_{s}\left(D_{s}^{j}\right)=0$, so condition (6) is satisfied.

It only remains to show that condition (4) is satisfied as well. All coalitions $D$ that contain player $i^{1}$ have $\lambda_{s}^{D}=0$, so for player $i^{1}$ this is immediate. Consider player $i^{j^{\prime}}$ for $1<j^{\prime} \leq k$. The only coalitions $D$ such that $i^{j^{\prime}} \in D$ and $\lambda_{s}^{D} \neq 0$ are of the form $\left\{i^{j}, \ldots, i^{c}\right\}$, for $1<j \leq j^{\prime}$. Equation (4) reduces to

$$
\rho_{s} w^{\prime}\left(\bar{y}_{s}^{i^{\prime}}\right)-\rho_{s} w^{\prime}\left(\bar{y}_{s}^{i^{1}}\right)-\sum_{j=2}^{j^{\prime}}\left(\rho_{s} w^{\prime}\left(\bar{y}_{s}^{i^{j}}\right)-\rho_{s} w^{\prime}\left(\bar{y}_{s}^{i^{j-1}}\right)\right)=0 .
$$

Finally, consider $i \in C \backslash I_{s}$. Note that all such players receive the same payoff in state $s$, and equal to $\bar{y}^{i^{k+1}}$. Since player $i$ is part of all the coalitions $D_{s}^{j}$, we have that equation (4) reduces to

$$
\rho_{s} w^{\prime}\left(\bar{y}_{s}^{i^{k+1}}\right)-\rho_{s} w^{\prime}\left(\bar{y}_{s}^{i^{1}}\right)-\sum_{j=2}^{k+1}\left(\rho_{s} w^{\prime}\left(\bar{y}_{s}^{i^{j}}\right)-\rho_{s} w^{\prime}\left(\bar{y}_{s}^{i^{j-1}}\right)\right)=0 .
$$

Thus $\bar{y}^{C}$ satisfies all the first-order conditions. It follows that there is no $x^{C}$ such that $x_{s}^{C} \in \mathrm{C}\left(\Gamma_{s}, C\right)$ for all $s \in S$, and $u^{i}\left(x^{i}\right)>u^{i}\left(\bar{y}^{i}\right)$ for all $i \in C$.

We show next that $u^{i}\left(\bar{x}^{i}\right) \geq u^{i}\left(\bar{y}^{i}\right)$ for all $i \in C$. For all $s \in S$, it follows from the definition of a rule that $\sum_{i \in C} \bar{y}_{s}^{i}=v_{s}(C)$ and $v_{s}(C) \leq \sum_{i \in C} \bar{x}_{s}^{i}$. Using the definition of the CEA rule it follows that for all $s \in S$ and $i \in C, \bar{y}_{s}^{i} \leq \bar{x}_{s}^{i}$. Since the utility function is monotonically increasing, we have that $u^{i}\left(\bar{x}^{i}\right) \geq u^{i}\left(\bar{y}^{i}\right)$ for all $i \in C$. Therefore, there is no $x^{C}$ such that $x_{s}^{C} \in \mathrm{C}\left(\Gamma_{s}, C\right)$ for all $s \in S$, and $u^{i}\left(x^{i}\right)>u^{i}\left(\bar{x}^{i}\right)$ for all $i \in C$, thereby showing part (b) of Theorem 3.8 . 
In cooperative game theory, it is standard to motivate allocation rules by providing convincing axiomatizations. For bankruptcy games, many appealing axiomatizations exist, leading to many possible rules. Theorem 4.3 implies that if one cares about enforceability of rules in the absence of commitment, and one would like to use a rule with a convincing axiomatization, one should use the Constrained Equal Awards rule.

\section{Conclusion}

In this paper we have introduced uncertainty into bankruptcy games. Since in reality the values of assets in a bankruptcy situation, as well as the claims of the players involved, are uncertain, this is a natural and important extension. In this paper we consider allocations, which are stable in the absence of commitment possibilities. Stability would mean here that no coalition has a credible deviation at any decision node. These considerations lead us to apply the concept of the Weak Sequential Core to stochastic bankruptcy games.

A rule assigns an allocation to each bankruptcy game, where the allocation divides the estate in such a way that every player gets a non-negative amount not exceeding his claim. For deterministic bankruptcy games, it is well-known that a rule leads to an allocation in the core. For a stochastic bankruptcy game, a rule assigns a state-contingent allocation with the property that the state-contingent estate is divided in such a way that every player gets a non-negative amount not exceeding his state-contingent claim. It is straightforward to apply the well-known allocation rules as suggested in the literature on deterministic bankruptcy games to the stochastic setting. We demonstrate that none of the rules typically proposed for bankruptcy situations belongs to the Weak Sequential Core, with the exception of the Constrained Equal Awards rule.

\section{References}

Aumann, R. J., And M. Maschler (1985): "Game Theoretic Analysis of a Bankruptcy Problem from the Talmud," Journal of Economic Theory, 36(2), 195-213. 
Chun, Y., J. Schummer, and W. Thomson (2001): "Constrained Egalitarianism: a New Solution to Bankruptcy Problems," Seoul Journal of Economics, 14, 269-297.

Curiel, I. J., M. Maschler, and S. H. Tiss (1987): "Bankruptcy Games," Mathematical Methods of Operations Research, 31(5), 143-159.

Curiel, I. J., G. Pederzoli, and S. H. Tijs (1989): "Sequencing Games," European Journal of Operational Research, 40(3), 344-351.

Dutta, B., And D. RAY (1989): "A Concept of Egalitarianism under Participation Constraints," Econometrica, 57(3), 615-635.

Granot, D., M. Maschler, G. Owen, and W. R. Zhu (1996): "The Kernel/Nucleolus of a Standard Tree Game," International Journal of Game Theory, 25(2), 219-244.

Habis, H., And P. J. J. Herings (2011): "Transferable Utility Games with Uncertainty," Journal of Economic Theory, 146(5), 2126-2139.

Kranich, L., A. Perea, and H. Peters (2005): "Core Concepts for Dynamic TU Games," International Game Theory Review, 7(1), 43-61.

Littlechild, S. C., and G. Owen (1973): "A Simple Expression for the Shapley Value in a Special Case," Management Science, 20(3), 370-372.

O'Neill, B. (1982): "A Problem of Rights Arbitration from the Talmud," Mathematical Social Sciences, 2(4), 345-371.

Piniles, H. (1861): Darkah shel Torah. Forester, Vienna.

Predtetchinski, A., P. J. J. Herings, and A. Perea (2006): "The Weak Sequential Core for Two-period Economies," International Journal of Game Theory, 34(1), 55-65.

RAY, D. (1989): "Credible Coalitions and the Core," International Journal of Game Theory, 18(2), 185-187.

Thomson, W . (2003): "Axiomatic and Game-theoretic Analysis of Bankruptcy and Taxation Problems: A Survey," Mathematical Social Sciences, 45(3), 249-297. 
Discussion Papers published in 2012

Judit Karsai: Development of the Hungarian Venture Capital and Private Equity Industry over the Past Two Decades. MT-DP 2012/ 1

Zsolt Darvas: A Tale of Three Countries: Recovery after Banking Crises. MT-DP 2012/ 2

Zsombor Z. Méder - András Simonovits - János Vincze: Tax Morale and Tax Evasion: Social Preferences and Bounded Rationality. MT-DP 2012/3

Fertő Imre: Szerződések kikényszeríthetősége a magyar élelmiszerláncban: a kis- és közepes vállalkozások esete. MT-DP 2012/ 4 